\title{
Changing Dynamics of Old Markets in Heritage City of Mysuru
}

\author{
Zahra Bathool ${ }^{1}$, Prof. B.Shankar ${ }^{2}$ \\ ${ }^{1}$ Research Scholar, School of Planning and Architecture, University of Mysore, Mysore, India \\ ${ }^{2}$ Professor of Urban and Regional Planning, School of Planning and Architecture, \\ University of Mysuru, Mysuru.India
}

\begin{abstract}
.
The markets reflect the diverse institutions of trade and economy in the city. A market space is not merely where people meet to exchange trade, but, a microcosm of incessant public images where the city fosters greater connection and engagement in terms of providing income, employment, and a community space for the locals to meet and greet. The old markets are the part of heritage city of Mysuru, which are the tangible heritage and are located judiciously as a common ground, where they act as connecting points in reasonable walking distances along the planned and plotted residential areas of the city. They were designed as a place to socialise and to foster the community diversity that co- existed in perfect harmony for over 100 years; such that the Mysuru palace forms the functional administrative core and the emergence of markets from the nodes transpired with permanent, semi-permanent and mobile vendors at the open spaces with a profusion of various merchandises. Over the years, the centuries old market places are unarchaic due to lack of proper maintenance; and are in constant debates after the collapse of two of the most important market spaces, due to physical, environmental, social and managerial aspects, which were called for restoration and conservation in the recent media agitation. This paper attempts to respect the changes in-time, right from the advent of the public markets in an effort to look at strategies that would alter the facets of preservation of its holistic heritage by improving the quality of life through place making to cohort the dynamics in terms of celebrating the relevance of public markets and their sphere of influence.
\end{abstract}

Keywords: Place-making, Public Markets, Heritage, Significance, Sphere of Influence 


\section{Introduction}

Market spaces are great public spaces, where the life of the city is envisioned. Markets encourage a broad range of density, diversity and "heads-up" encounters of social interaction and economic exchange of the city through its people, information, culture and the generated demand for the trade of goods and services reducing societal antagonism and developing a community's individuality. While the fundamental function of markets as a trading space has not changed for centuries, they are also regarded as a cultural space where a glimpse of the local lifestyle can be seen (Ashworth, 2000[1]; Crespi \& Perez, 2015[2])

The idea of a public market creates positive associations for many people, but a concrete common definition of a public market can sometimes be elusive. For some people, the iconic image of a public market is the line of tents covering vendors in an open-air market; for others, it is the colorful display of food and crafts along the stalls of a market hall. In fact, a rich diversity of public markets exists around the country and around the world; and while sometimes confusing, this broad range of market types is ultimately an asset, allowing markets to meet a wide variety of needs for vastly different communities. [3]

Markets have a mix of uses and meanings serving the interests and needs of local residents, while building strong connections between history and communities. However, when intrinsic cultural factors start fading due to the dominance of modernism through technological innovations and consumer preferences along with globalization, a relative dynamics begin from open air markets which are following the "Heads up" approach - a vibrant and colourful system which brings many people together on a common place, to closed and air conditoned "Heads down" approach which is very less or zero encounters with the community but just on the shopping. Based on the characteristics developed by the Project for Public Spaces three characters distinguish public markets from the other varieties of markets: the public goals (to serve wider goal such as supporting local farmers and small businesses, providing access to fresh food, draw a community together, or spurring the economic development); the public spaces (accessible and open to the public at large-inviting, safe and lively); and the local business (small businesses and local flavor is critical to the sense of identity) [4]

Mysuru is one of the cities with an ancient history, due to which its influence, settings and architecture have been developed on the planned character of its proposition, majorly developed as the princely capital of the Wodeyar's, the rulers of the region. The city has inspired many to think stateliness along with the architectural features which bring this unique character that you sense as you move through the city all along the horizon. One such planned group of buildings are the neighbourhoods and the judiciously planned market spaces around them. The development of the planned markets was commissioned after the Great Plague of 1898 to improve the city soon after, as greatly social, cultural and public spirited architectural masterpieces capturing the essence of the city for its design, planning and aesthetics.

However, within the course of time, the traditional market spaces have grown and developed without regard to the idealised meticulous planning systems developed to showcase the richness of the first planned city of Asia. A dynamic dissent has triggered the role transformation from the philosophical conceptions to the societal needs and policies of the Mysuru City corporation authroity. The impending divergence of development from its fort walls, to an expansive mode with the monumental scale of the buildings and the streets and its changing landscapes 
considered time bound, in relative identification of serving a new trend of improving the quality of public spaces, while altering the old to new elements. The study is investigating on the significant qualities of the traditional market spaces, through the existing footprint which has remained the same from the past century, but the edges have gone through numerous urban transformations. The study also examines the relevance of regulatory and planning tools to historic Indian traditional markets and its conservation strategies so as to sustain the city's resources.

\subsection{The Significant Factors of the Traditional Markets of Mysuru}

The rulers of Mysuru encouraged trade and commerce by laying good roads in the kingdom, introducing a unified system of currency and standardising weights and measures in the kingdom. They began organizing guilds as an important feature of the city system within a small walkable radius and having to plot the city's first three markets according to the coordinatesone in the Center, one in the North and the other in the South (Figure 01). Mysuru's planned traditional markets are basically vegetable markets, regulated markets, and retail markets.

The market is a hub of activities which sells every commodity from the birth of a child to the death of an individual, Products relative to daily activities, all kinds of greens, fruits, vegetables, flowers and all are grouped and sold in one single cluster. It has around 1500 traders, including small traders in the markets, selling all kinds of goods, having a crowd of around 10 to 15 thousand people who are of varied genders, age groups and cultural backgrounds on regular days and 20 to 30 thousand people on special days, including festivals. The market space is associated with activities and its hierarchy, while the chaos of interaction happening between the buyer, retailer, commission agent, administration and the labourer (Figure 02)[5]. This circle of contained significance is visibly noticed in the engagement of spatial integration in all the three traditional market spaces of Mysuru.

\footnotetext{
\begin{tabular}{|l|l|l} 
Figure 01: The proximity circle of activity & Figure 02: The Chaos of the power-hierarchy
\end{tabular}

zones around the 3 markets
} 


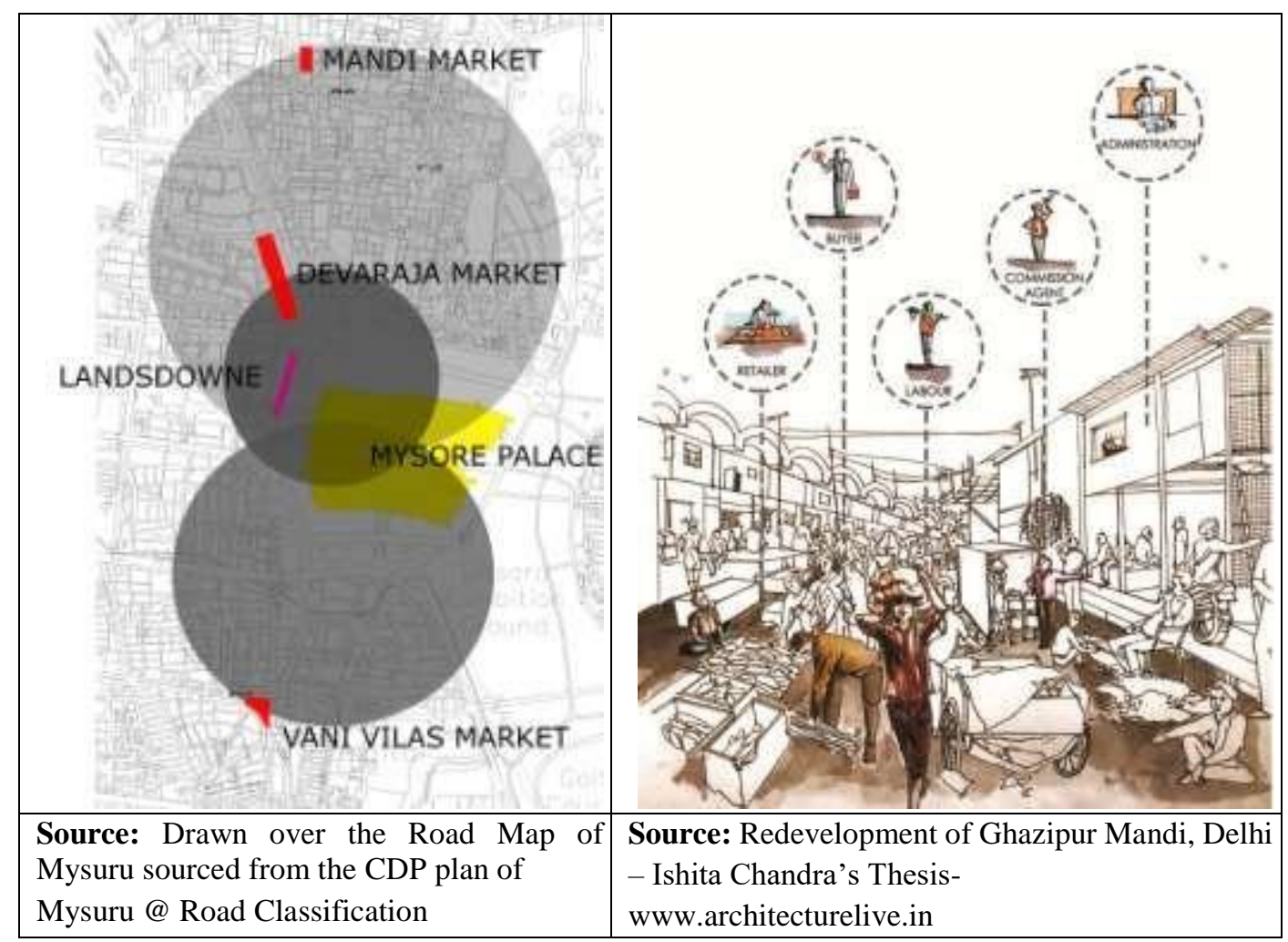

\section{A. Devaraja Market:}

The almost 133 year old Devaraja market dates back to the reign of Tipu Sultan in the $18^{\text {th }}$ century. At the time it took the form of a small weekly market where fresh vegetables and fruits were probably the most traded items called the Devaraja Mohalla which basically is the origin of the city too. The Devaraja Market was expanded into its present form retaining the name of the mohalla, constructed above the Dewan Poornaiah Canal that supplies drinking water to the Mysuru Palace and it has been named in 1925 after Dodda Devaraja Wadiyar(1659-1673). It is spread around 3 acres with around 842 shops which are built and around 250 temporary makeshift stalls.

The market has an architectural façade that faces the street on four sides while internally there are large open spaces for the formal market building to function as if it were an informal marketplace. There are shops at the edges of the street which are larger and face the main street. The inner semi enclosed-shops are open towards the large open space and are arranged along three aisles that run through the length of the market. The vast panorama of this dotted planning system where an urban space is embedded aesthetically within the architecture of a building with wooden rafters and stone masonry walls in the presence of a public square that lies outside, as a private square within it for the exclusive use of traders is something very unique about these markets.

The market complex is not protected by the fire, witnessing many major fires that destroyed several shops and the collapse of a tower during its nearly a century of existence, is in a dilapidated state. A total of 150 shops were destroyed in the fire in 1981, 175 shops in 1990, and 30 in 1999. The tower of the market facing the "Ane Sarot" collapsed which, however, was 
repaired by the Mysore City Corporation.Not much has been underatken by the civic authroitites either to make it fire resistant by introducing water hydrants at regular intervals or even personally by the traders who have been running the business everyday. Considering the narrow passages and the smaller entrances that lead you to the market, its far more difficult for the fire tenders to reach out during an emergency too. The distribution of built verandahs against the unbuilt pedestrian spaces is also sometimes unfaintly during such emergencies(Figure 05).
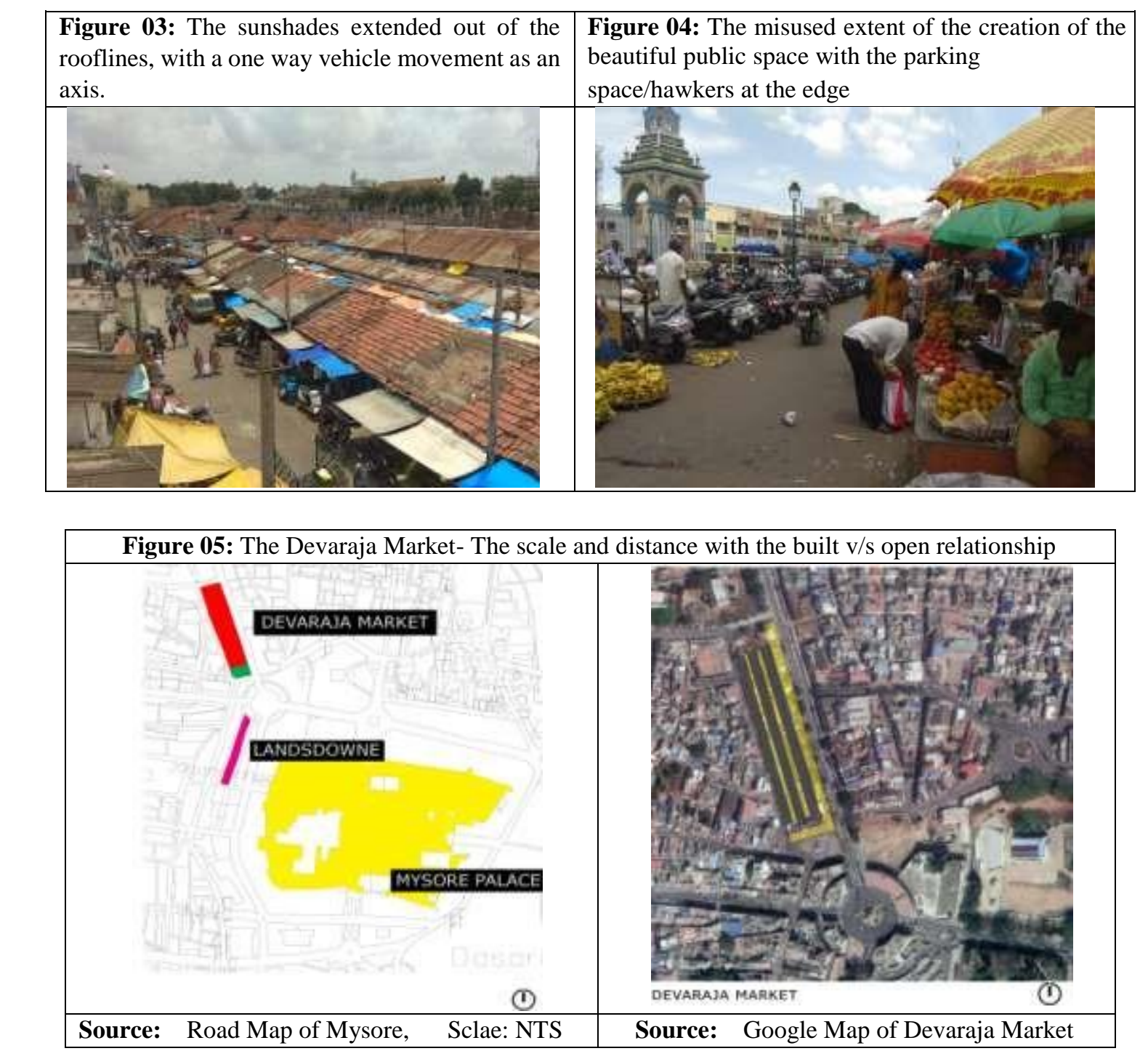

\section{B. Vani Vilas Market:}

The Vani Vilas Market named after the queen, Maharani Kempa Nanjamanni Vani Vilasa Sannidhana, started around almost 90 years ago was gifted to the City Corporation by the Maharajas. It houses around 90 stalls, which are permanent and situated at the edge of a downtown neighbourhood, which was accessible to the people who work for the royals. It has a lot of intermediary space for temporary makeshift shops and even hawkers. This catalogue of shop size typologies cater better to the needs of the merchants pertaining to the larger scales of business. Not very distant from the Palace, it has two entrances, variably at the edge of the street and facing the main commercial MG road, a busy commercial centre which is devoid of any identified parking, shows that this was planned for the pedestrians. The market is not very 
planned for various types of products, but mainly retail, as only the main shops are put up rest all are today acting as godowns with not much activity happening either inwards or outwards in terms of social gathering.

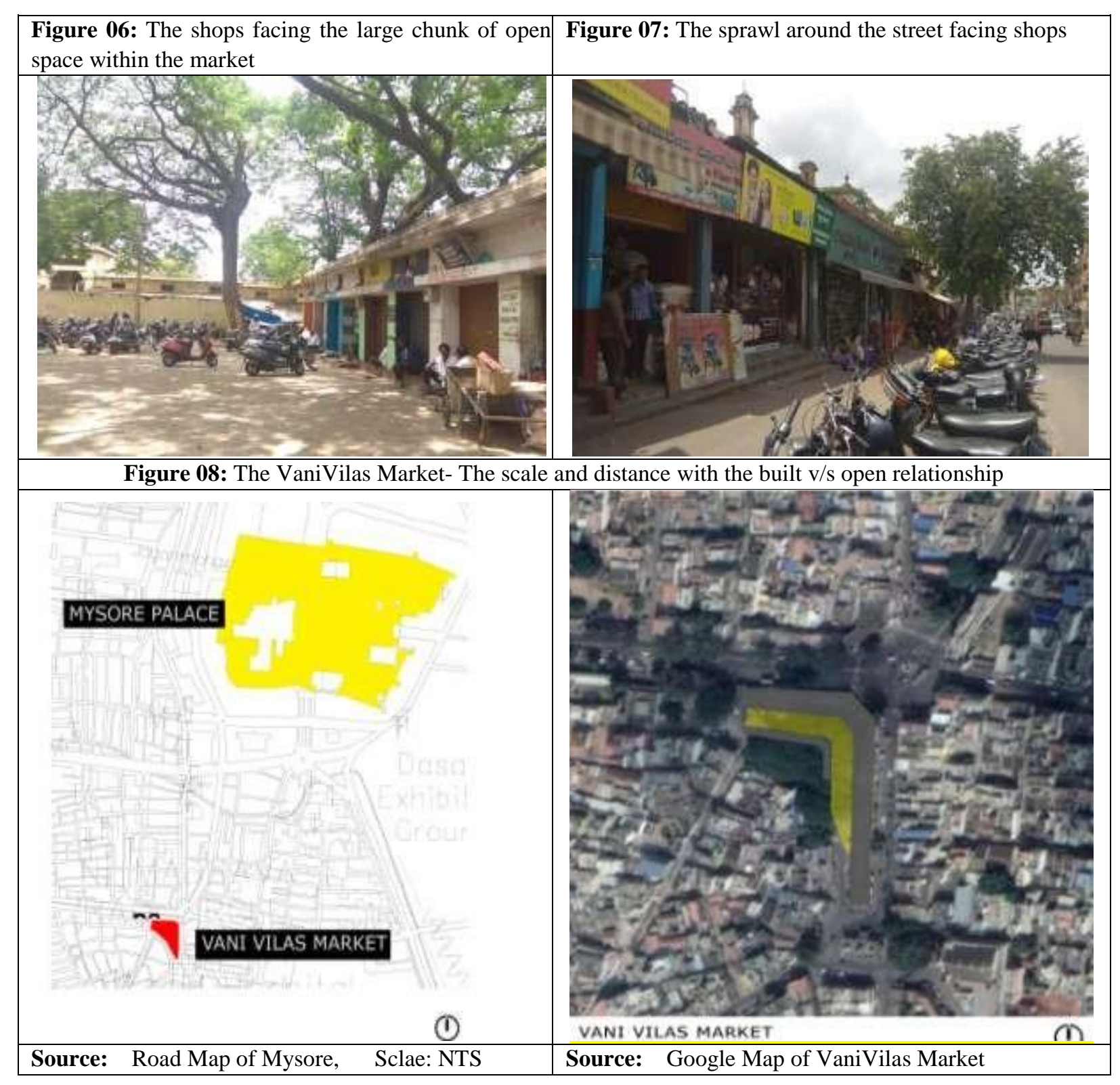

Figure 09: The VaniVilas Market- The form and architecture 


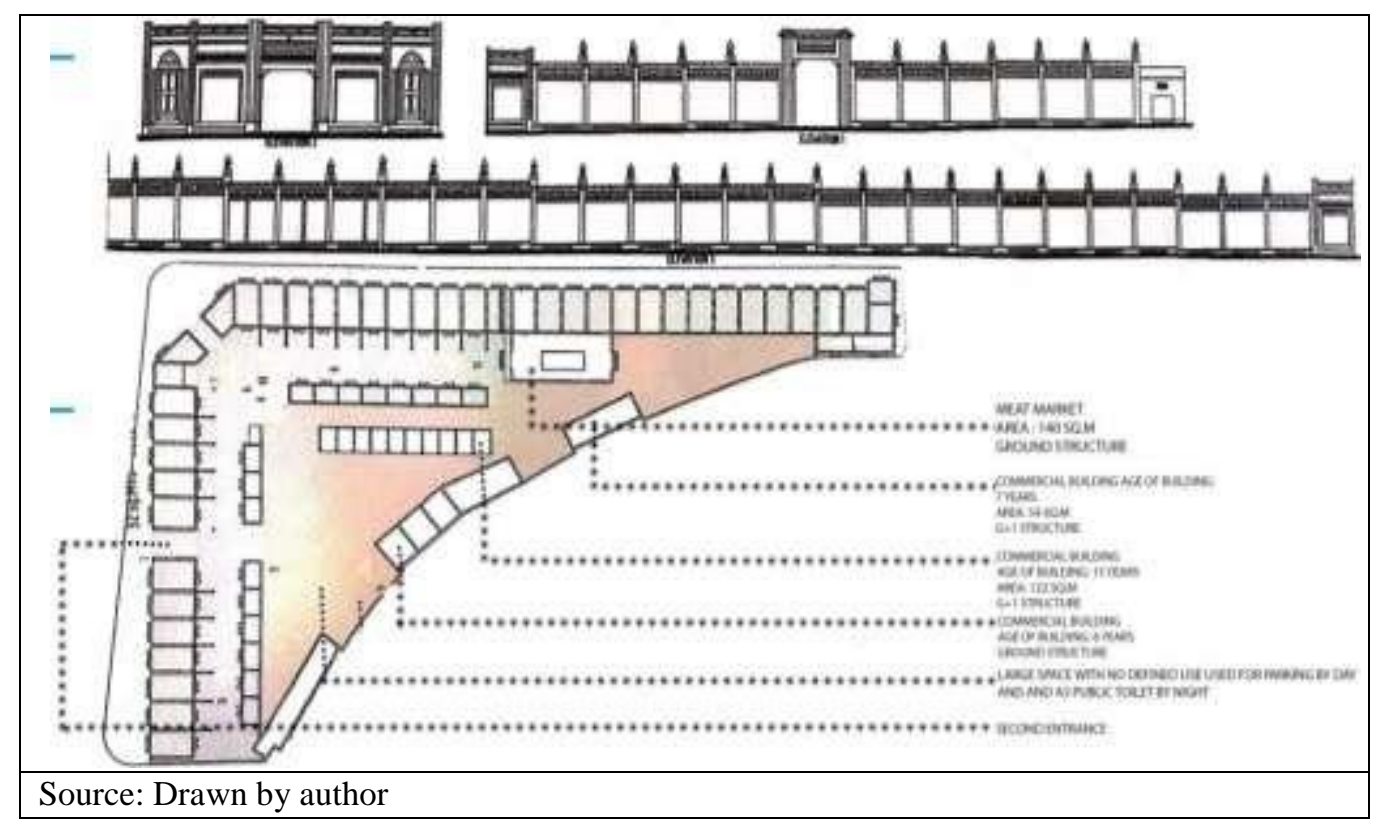

Today, most of the shops at the interior of the market are converted as godowns by the shop owners and a huge lung space, unfortunately people are parking their 2 wheelers during the day (Figure 06) which could otherwise have a lot of other activities, if planned as a better public space with the right edge treatments and the character spaced and well related to retain the city's past with the same intention of its formation.

\section{Mandi Market}

The 163 year old Mandi market has 135 stalls mostly planned for trading of food grains and other produces, brought from neigbouring villages chiefly from the fertile area of the river Cauvery, and sold them in this Pete or Market. The mandi market was very congested, as it was planned and designed along narrow roads basically designed for the bullock carts, which brought in the food grains. This planned marked had shops which were permanent and lined across both the alleys of the space, with very minimal hawker space.

This was done to store the food grains away from theft and misuse of the products. It has two entrances and faces streets on both sides of the enclosed rectangular market area of today. It is a far better maintained market than the much larger vani vilas market, as the zeal of the market is still alive with the traders and the buyers having a greater symphony with the metamorphosis of the way the market has stayed. The Slaughter house and the vegetable market along with the perfumes/ scents have always remained the part of the maintained heritage and the urban transformation that has been carried in this market is because of the context.The need of the hour is to study the changing market scenes and set up an influence on the surrounding environment as a heritage structure. And if the open versus closed spaces are studies, you can easily make out that the transformation this market has achieved is at the highest in terms of the contexual dynamics. 

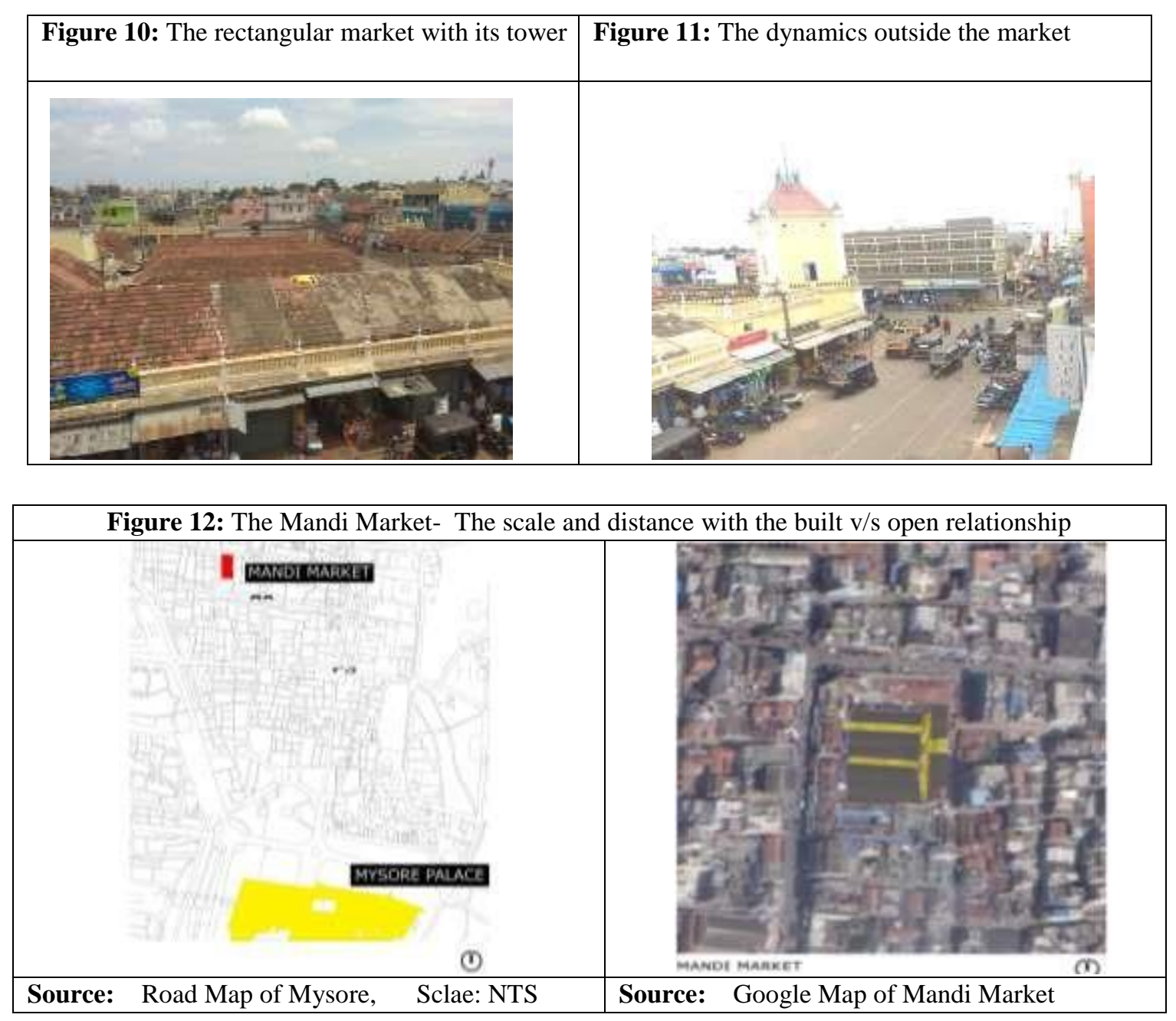

\section{Landsdowne market:}

The Landsdowne building market originally built in 1892 to commemorate the visit of the Viceroy and Governor-General of British India, Lord Lansdowne while Maharaja Chamaraja Wadiyar was ruling the erstwhile Mysuru State - is another classic example of tangible heritage through a market space. The market with around 90 stalls is built with wood, iron and limestone and around 200 girders(pre named as Range bazaar before the inauguration), and that the primary reason was to house Sharada Vilas primary school at the first floor and some retail shops, and later after the school shifted - it turned out to be multiples of stationary shops, the second hand books, the photo copy shops, the poster and movie CD shops, the ones who did typing, data editing shops and advocates.

The myopic approach in restoring or even protecting these decayed marvels by the current administration-the Mysuru City Corporation, through its step motherly attitude has led to the fall of the two important heritage monuments in town- The Devaraja Market collapse which happened in 2005 and the crumbling of the Landsdowne market in 2012- a lifeline to over 100 shop keepers. In other words, today when we try to weigh the situation between preserving the 
festooned heritage of an old charm city or even trying to modernize Mysuru. According to the statements in the media, where demolition is the cliché with respect to bringing the old world charm and reassuring the people that a new multi storied structure housing the same characteristics is entering the zone but with better facilities like parking and new shops for the people who lost their livelihood in the negligence occurred due to the collapse.

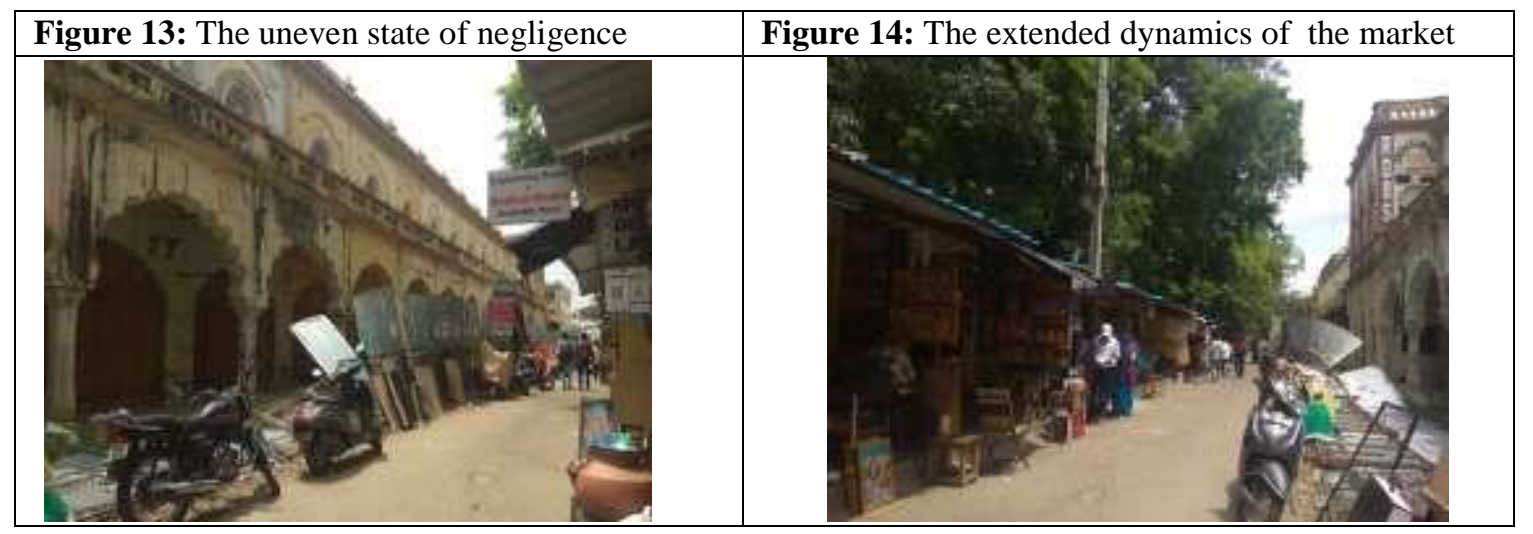

The emotional connect that the owners, shop keepers and the heritage committee in protecting the structures is due respect to conservation, but not demolition and reconstruction. The significance factors when tried to be assessed based on quality, common dynamics were noticeable even with varying contexts. More scope of public and cultural exchange is visibly noticed in the legibility characters, so place-making plays considerate importance in attending to the "meanings" which are lost with the changed dynamics around the markets.

Table 01: Quality Significance factor analysis of the markets

\begin{tabular}{|c|c|c|c|c|}
\hline $\begin{array}{c}\text { Quality Significant } \\
\text { factors }\end{array}$ & Devaraja Market & Vani Vilas Market & Mandi market & Landsdowne market \\
\hline Nature+Identity & $\begin{array}{l}\text { Commercial-Core- } \\
\text { City center }\end{array}$ & $\begin{array}{l}\text { Commercial- } \\
\text { South - Purams }\end{array}$ & $\begin{array}{l}\text { Commercial- } \\
\text { North-Mohallas }\end{array}$ & $\begin{array}{c}\text { Commercial- } \\
\text { Much larger in scale }\end{array}$ \\
\hline Form/Elements & $\begin{array}{c}\text { Wide array of } 840 \\
\text { shops alleyed across } \\
\text { three rows of } \\
\text { rectangular built shops }\end{array}$ & $\begin{array}{l}\text { L- Shaped facing the } \\
\text { street are the } 90 \\
\text { shops, with a wide } \\
\text { open space in the } \\
\text { center }\end{array}$ & $\begin{array}{c}\text { Hard to ascertain the } \\
\text { beginning and end, as } \\
\text { the } 130 \text { shops located } \\
\text { on either side of the } \\
\text { market }\end{array}$ & $\begin{array}{c}\text { Permanently } \\
\text { structured shops }\end{array}$ \\
\hline $\begin{array}{c}\text { Metaphor of Built Vs } \\
\text { Open }\end{array}$ & $\begin{array}{c}\text { Urban sprawl with } \\
\text { street like smaller } \\
\text { spaces }\end{array}$ & $\begin{array}{c}\text { Centered and hugged } \\
\text { hierarchy }\end{array}$ & A box within a box & Uncluttered \\
\hline Texture & $\begin{array}{l}\text { Ornate features and } \\
\text { embellishments on the } \\
\text { facade }\end{array}$ & Parapet merlons & Dominant lotus bases & $\begin{array}{c}\text { Heavy mix of } \\
\text { Sarcenic inspirations }\end{array}$ \\
\hline $\begin{array}{c}\text { Informal chaos of } \\
\text { stakeholder (buyer, } \\
\text { retailer, labourer, } \\
\text { vendor) }\end{array}$ & $\begin{array}{l}\text { Dynamics of products } \\
\text { and design chaos }\end{array}$ & $\begin{array}{l}\text { Dynamics of } \\
\text { interaction and } \\
\text { stakeholder }\end{array}$ & $\begin{array}{l}\text { Dynamics of } \\
\text { circulation and } \\
\text { stakeholder }\end{array}$ & $\begin{array}{l}\text { Dynamics of design } \\
\text { and professions }\end{array}$ \\
\hline Contextual activities & $\begin{array}{c}\text { Varied- Fruits, } \\
\text { Vegetables and } \\
\text { Flowers, Slaughter } \\
\text { house } \\
\end{array}$ & $\begin{array}{l}\text { Non perishable goods } \\
\text { and groceries, puja } \\
\text { items }\end{array}$ & $\begin{array}{l}\text { Varied- Fruits, } \\
\text { Vegetables, Scents, } \\
\text { Slaughter house }\end{array}$ & $\begin{array}{l}\text { Non perishable- } \\
\text { Stationary relative }\end{array}$ \\
\hline Junctions & $\begin{array}{l}\text { "L" shaped with } \\
\text { permanent and semi } \\
\text { permanent stalls }\end{array}$ & $\begin{array}{l}\text { "T" shaped permanent } \\
\text { stalls and also flexible } \\
\text { table top vendor } \\
\text { spaces }\end{array}$ & $\begin{array}{l}\text { "L"shaped stalls with } \\
\text { a clear volume } \\
\text { difference with the } \\
\text { types of business }\end{array}$ & Parallel crossways \\
\hline
\end{tabular}




\begin{tabular}{|c|c|c|c|c|}
\hline Structure & $\begin{array}{c}\text { Tiled roofing with } \\
\text { double side slope } \\
\text { supported by steel } \\
\text { beams }\end{array}$ & $\begin{array}{c}\text { Flat roofs, mostly } \\
\text { with a large chunk of } \\
\text { unplanned spaces }\end{array}$ & $\begin{array}{c}\text { Mansard roofing, spill- } \\
\text { out towards frontages }\end{array}$ & $\begin{array}{c}\text { Lime mortar and } \\
\text { wooden rafters }\end{array}$ \\
\hline Aesthetics & $\begin{array}{c}\text { Trend of time-Pure } \\
\text { and Orderly }\end{array}$ & $\begin{array}{c}\text { Double storied facade } \\
\text { with one floor spaces } \\
\text { habitable- false facade }\end{array}$ & $\begin{array}{c}\text { Native to the context- } \\
\text { built fabric }\end{array}$ & $\begin{array}{c}\text { Ornamental festoon of } \\
\text { the city }\end{array}$ \\
\hline
\end{tabular}

\section{Dynamics of Culture and Society: The Produce and the Process}

Cultural dynamics is considered as an exchange of conversational growth through formation, maintenance and transformation becoming inevitable due to the cultural factors recognizing globalization, decentralisation and digitalization which affect the societal comfort aspect. Markets of Mysuru began their role from the highly culturally distinctive mohallas (Figure 15), that lived past the history of mysuru and its regional context. As a tool to accomodate the need of every consumer, special lanes were reated for all the items, like the flower lane, fruit lane, the green lane, the vegtable lane and produces were characterized to have outlived their original economic functions and turned into centers of culture and tourism within the blocks of sale, thereby acquiring quantitative characteristics quite unplanned for in their architectural origin and aesthetics.

Historically, the kings also used to have annual events of "the market shows" which would keep the cultural and social factor alive with each of the stall owner displaying the best of their work out of the produce that was being sold during the dasara season. This factor combined historical facts and anecdotes with a harmonious combination of both natural and built heritage. With the right amount of facilities being considered within a walking distant and to safeguard the accessibility factor from decay, it is necessitated to take appropriate sociocultural planning measures to conserve the heritage areas of the city and to confront on the holistic and integrated approach through this elemental study.

Figure 15: The Mohallas of Mysuru with the triangulated markets as equal distribution
Figure 16: The accessability or the serving zone of each of the market 


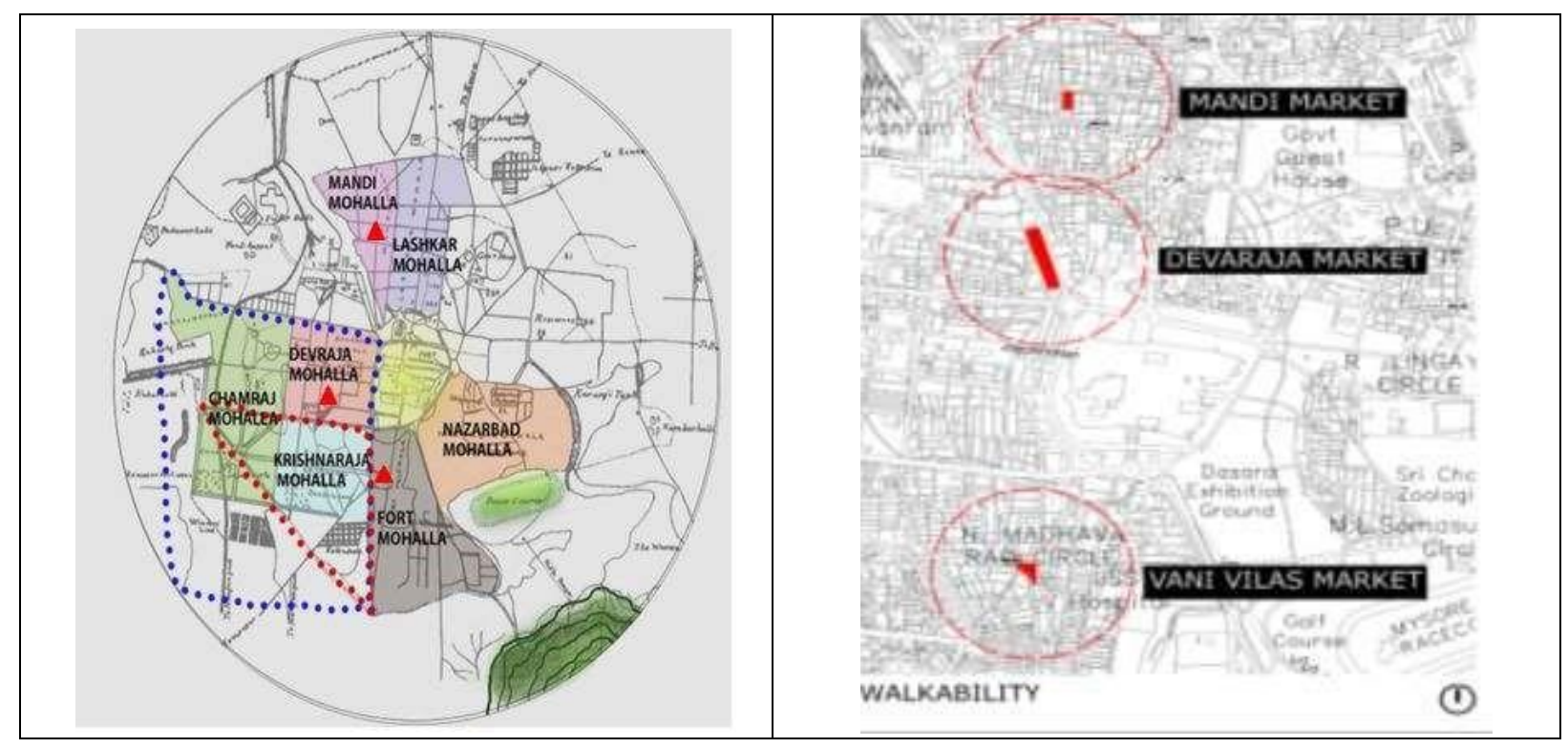

The Devaraja Market, located in the city centre, was the grandest of the three and was "one of its kind" during its days of glory and dominated the city skyline and became synonymous for the sight and aroma of Mysuru. Devaraja Market was a beehive of activity that opened for transaction early in the day and served thousands of customers, making it a popular spot for acquiring pride of place as a "commercial hub" where business is still conducted. Massive in its sprawl, Devaraja Market is spread over 15,765 sq. m. and the vegetable market alone occupies about $14,885 \mathrm{sq}$. $\mathrm{m}$. It is located in the precinct of a heritage clock tower. The local people call it the Chikka Gadiyara or the small clock tower built in 1886 (Figure 17) as its perfect cynosure. It was commissioned in honor of the then British Viceroy of India, Lord Dufferin. He was the first Viceroy of the colonial India to pay a ceremonial and friendly state visit to the invitation of the Maharaja of Mysuru.

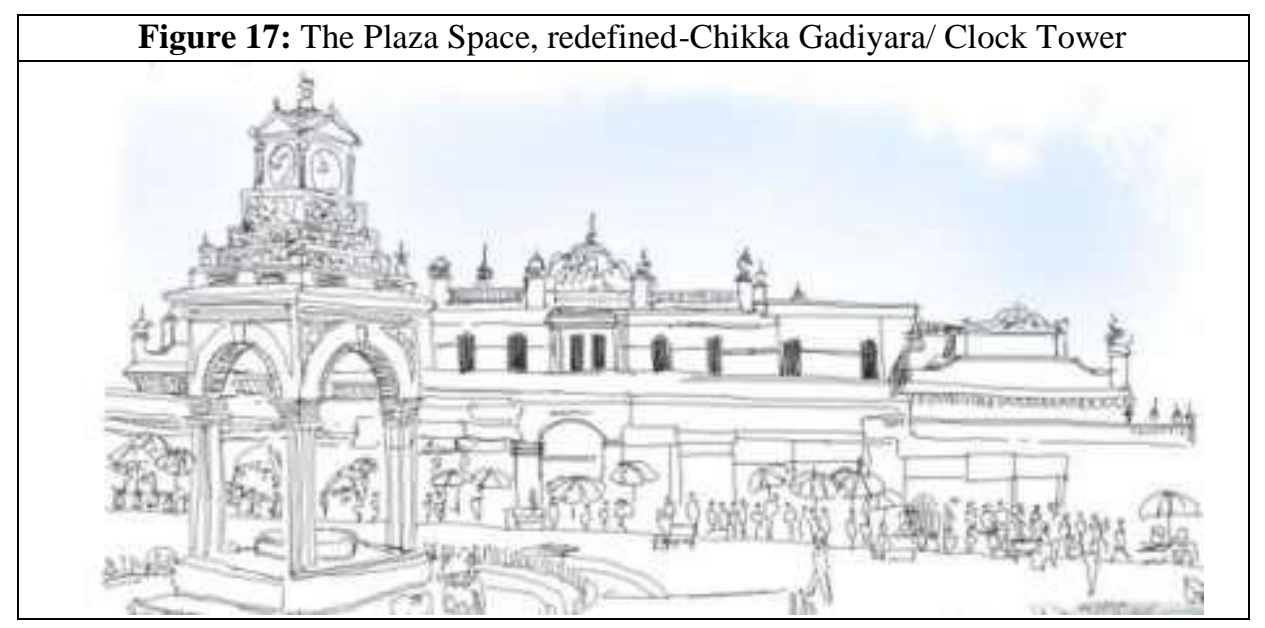

The clock tower is built on a foundation of eight pillars covered by railings. A decorated fountain at the center is the showpiece of the structure. The clock tower underwent restoration in 2012. The space which was was formerly used by hawkers and vehicle parkers were vacated and a plaza was redesigned with seating and spaces to gather in communion. This particular place has a lot of meaning, for the people of Mysuru as it is more of an emotional relationship 
with its attributes, activities and meanings. The Mysuru culture and its past experiences, backgrounds, memories, personality, knowledge, attitude, motivations, beliefs, age and gender influence the perceived sense of place here. This is the context at which the culture gained its society. A "heads-up" encounter is the factor of community spacing.

The Vani Vilas Market has a lot of scope to work on the cultural society factor as noticed from its non functioning clock tower which has not developed the pressure of society, because of the fact that the existing neighbourhoods around this market of 1.2 acres have their own communion spaces. The shopkeepers also have a clear demarcation of areas with a private court space in between, which was planned for a certain spill out of the stakeholders. The Market does not have capacity to accommodate the present on-going business. Also it cannot hold many people particularly the days preceding the festivals and fairs due to the shared revenue between the stalls here and the nearby regulated market which is at a much better catchment than the current location.

The Mandi mohalla with its mansard roofing lies in a crowded frenzy neighbourhood, which never sleeps. With the cultural dynamics there currently with respect to the diversified variety served on platter. It also is centered around the textiles and electronics markets closer-by. Thus totally patronising commercial activities to the hub.Though the roads are narrow, the culture and societal connections are wider. People throng near the frontages for a communion of the same level. A very organic Indian character, of increasing efficiency in terms of the "heads-up" encounter while the nearby sprawl is also very relative to the spacing.

The Landsdowne building which followed the same fate of the markets, is almost shut from functioning and has ever since been closed, and today it is being vandalised by street elements by misusing the facade to relieve themselves and further weakening the structure. Appropriating the contextual and dynamic anticipation of change between the traders and the consumers the following accelerations in terms of the shift in qualities and associations of memories were aroused.

The feeling of nostalgia around the Devaraja market, familiarity to the purpose or usefulness at the Mandi market,while appreciation of intentions to the technical image of the city planning system with the Vani Vilas Market. A new perspective of weaving the culture and the society through the planned communions in this day without losing its value and congruence is the intention to preserve its holistic heritage by improving the quality of life through place making to cohort the dynamics in terms of celebrating the relevance of public markets and their sphere of influence without losing their identity due to negligence, decay and disharmonious developments, which result in diminishing the form of the city.

\subsection{Sphere of Influence around the markets}

A Sphere of Influence is a tool to discourage sprawl and to encourage orderly changes while the present and the future policies are influencing each other to develop an immediate, long term facilities in the amended area mostly associated with services and the environment. To be a successful sphere of Influence, it should not be an independent element. Instead, it is an 
element of working framework which leads to the future development So, in terms of the three markets, when an influential analysis is made with the visual treatment (Figure 18) given to the markets and their contexts, the viscosity of its identity shadowed more towards the areas of edges, access, interaction and character.

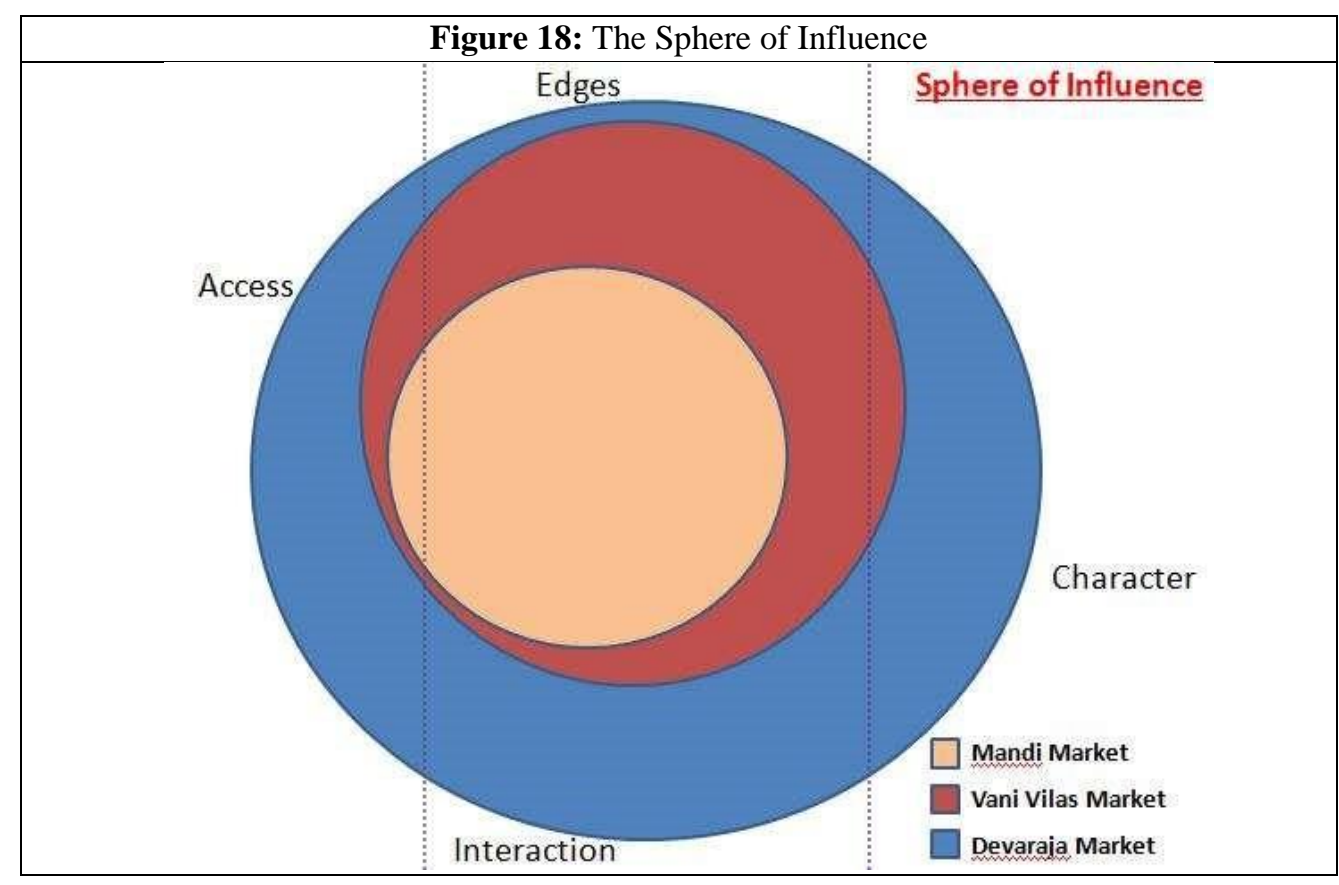

A study of the urban landscape of Mysuru and its market would remain incomplete without an analysis of the sphere of influence of the market and its boundaries which range from a distance of $656 \mathrm{M}($ Devaraja Market),876 M(Vani Vilas Market) and $1355 \mathrm{M}$ (Mandi Market) from the core of the city which is its main palace. Therefore, it is possible to conclude that Mysuru markets continue to exert the most powerful pull over this part of the city and its dependence on the everyday perishable and non perishable goods.However, further investigations are necessary to find out whether the expected breakpoints obtained coincide in terms of functional and other linkages as the above analysis states, as all the three are easily accessible and have a great edge significance factor too. More scope could be given to build up on the Interaction and character development of the markets through the attributes mentioned in the Table 02 below.

Table 02: The Influential attributes for the Sphere of Influence

\begin{tabular}{|l|l|l|l|}
\hline Attributes & Devaraja Market & VaniVilas Market & Mandi Market \\
\hline Size & Large & Medium & Medium \\
\hline Configuration & Permanent and temporary & Permanent & $\begin{array}{l}\text { Permanent } \\
\text { temporary }\end{array}$ \\
\hline $\begin{array}{l}\text { Tendency } \\
\text { Identification }\end{array}$ & Dense-walkable & Compact-Spread & Serried- walkable \\
\hline Node of exchange & Regional and local & Local and regional & Local and regional \\
\hline Perspective role & Macro & Macro & Micro \\
\hline
\end{tabular}




\begin{tabular}{|l|l|l|l|}
\hline Interaction & Socio-Cultural & Socio-Cultural-Religious & Socio-Cultural \\
\hline Quality & Homogenous, Sharpness & Realism & Dynamics \\
\hline Character & Navigable aisles & $\begin{array}{l}\text { Much open, devoid of } \\
\text { edges }\end{array}$ & Navigable aisles \\
\hline Degree of formality & Safe & Enveloped & Immersion \\
\hline $\begin{array}{l}\text { Recent } \\
\text { developments }\end{array}$ & $\begin{array}{l}\text { After the crash, the } \\
\text { demolished part is not } \\
\text { accessible and is awaiting } \\
\text { a nod to take a decision } \\
\text { between demolition and } \\
\text { reconstruction }\end{array}$ & $\begin{array}{l}\text { The design system is } \\
\text { vandalised but short of } \\
\text { community aspirations }\end{array}$ & $\begin{array}{l}\text { The harmony } \\
\text { of heritage is } \\
\text { neglected and } \\
\text { decayed }\end{array}$ \\
\hline
\end{tabular}

\subsection{The Pragmatism of Place making}

Rooted in community-based participation, place-making involves planning, design, and management. Place-making brings more life to the public spaces, and as we know, if the three markets and the Landsdowne market is considered for cultural place making and creative placemaking- it is about reinforcing happiness through strengthening "community identity", with "a sense of place" and leveraging "community, heritage and social functions" which could be added as policies by the city management. Monumental architecture plays an important role in attaching people to its place while understanding heritage as the backbone of any great community.

The study has looked into past, people and experiences and entwined a nexus to investigate the community based values, through a context of heritage while exploring social links of identity, place and practices to have a meaning with the specified "place". Indeed, heritage is not so much about the past as it is about the life of the past. Place making (Figure 19) involves an environment and culture being attached to the community through restoring the setting of the past by a sense of belonging. A program can be conceived in making it more pedestrianised, after looking at the accessibility area, and transforming the liveability of the communities to strengthen the centre around Devaraja Market and the Landsdowne market by including public initiated designs for public art, streetscape, and performance spaces to gather.

Figure 19: The place-making strategies 


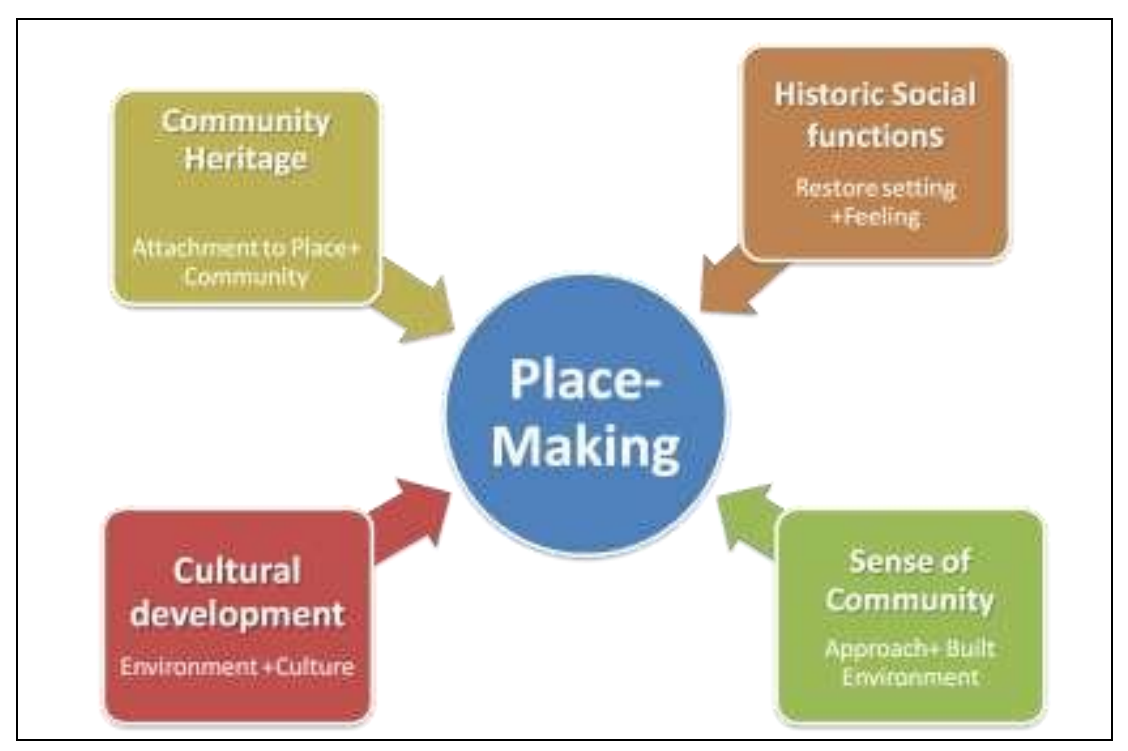

Pedestrian activities which do not need any vehicles or their interference can be provided with designated and allocated spaces for the hawkers outside such that the involvement of each person in the trading circle grows higher and brings back a more cultural sense to have valued products from the city sharing one prominent space in the public spaces such that any tourist/ visitor doesn't have to travel all the way to individual shops but comes here, to experience Mysuru in a walkability radius of $1 / 4^{\text {th }}$ of a mile by adding on more activities in the identified public spaces along the corridor of the market zones encouraging more civic dialogues, restoring a sense of city's pride and unity, improving the quality of place, strengthening cultural and economic viabilities and when all of this is cared for- the space become vibrantly sustainable too.

\subsection{Prevailing Issues and Concerns}

Certain potential strategies are pivotal in strengthening the confluence of public markets. A reduction in "heads-down" approach and familiarizing on the visible and quantifiable tangible factors to integrate community spaces with the government's policies every time a new master plan is updated. Identified concerns of the three markets, are:

- Huge competition from corporate vendors like More, Big Bazaar, Nilgiris, Reliance etc which are basically the " heads-down" approach factors

- No repairs done, even after major fires in the past- because the government is not achieving good rentals, so revival of the rental capacities, such that management of funds can be flown easier for uplifting the markets needs.

- Whatever renovation work is completed, it is all privately done by the shopkeepers/tenants

- Maintenance issues like waste management and clearance of garbage is essential twice a day

- Non provision of water facility to drink or even a toilet in the premises of the markets are absent. Even though toilets were built at 3 places, earlier-they work as shops today as they were under utilised 
- Vendors are not given proper spaces to park their business, improper plotting invites their interference

- Vehicular congestion and non adequate parking facilities all around the three markets is noticeable

- During emergencies, no market has a doctor-on-call

- Water seepage into most of the shops during rainy seasons, the make shift tarpaulins do not give enough coverage during the rains

- The water which enters the space has no percolation space or slope, nor does it have any designated water channel system to let out the water back to the ground

- Lack of space to expand

- No design team in the heritage cell to work on policies mentioned for space improvements

\subsection{Strategies for improving the Public Markets}

Markets are hybrid public spaces requiring fresh thinking beyond historical understanding. The markets are dynamic process and an essential aspect of any successful design and management process. The three markets of Mysuru have worked on many time changes reflecting the transformation and the need of a focused approach to reflect local conditions, culture, and the organizational needs of each market for place-making through its own sphere of Influence;

1. With the growth in population, the need for better planned markets in the accessibility radius to be added with respect to the Mohalla theory of the kings.

2. The old and the new proposed markets should fall under some market policy and development and follow a defined market policy at every master plan that is revised, which reminds of the development of cultural infrastructure.

3. Design principles and Planning guidelines to play an important role in Place-making

4. Map the existing distress caused to the structures, after studying the previous documentation work done by JNNURM and the heritage task force

5. Establish a material morphology of the strength of materials by continuing to protect the the dilapidated structures of the three markets

6. Understand the various building construction materials and techniques and develop a team to manage its reconstrution and renovation without causing harm to the heritage.

7. Spacing out hawkers in a specifically identified zone in every market space without cordoning off to the trading area

8. Accelerate the vision of Mysore city, to aesthetically improve Mysuru's image and bring tourists to Mysore all around, not just during the dasara time

9. Bring in more proactive scope for positive competition amongst the sellers and the buyers through interactive places to formally socialize as a one stop destination for many activities

10. Identifying the heritage conservation assets, like the zoning of activities and facilitating participation of cultural activities within the $1 / 4^{\text {th }}$ mile radius.

11. Devaraja market to have better planned spaces, around the Ane Sarot street, which is not looked at every dasara, only the other 3 entries are preferred for re-painting. These stalls have always been hit by fire, and many electrical snags which has caused the market a wide array of destruction. Slaughter houses to be lined and cleanliness regularised at frequent time intervals. The fruit mandi around to be regularised with proper structural maintenance 
with proposing a separate circulatory path for the goods vehicles. Having identified garbage bins and cleared at regular intervals. Proper toilets to be set up with regularised water inflow and outflow. Ascertain and design an uniform signage system which could meticulously arrange the role of the visual perspective of scale and proposition

12. Vani Vilas market to be adequately planned for systematic spacing of hawker alleys and provide a communion space with the formal spaces integrated without cordoning off to the trading area. Proper utilization of such public traditional market spaces and influence tourist inflow while considering place making. A diversity of age, gender, and cultural background should be accommodated to assure an inclusive social space. Children's play and activity needs to be integrated into the design. The spaces of movement and social encounter, the interplay between the alleys and the market landscape, should be coordinated with the sedentary spaces of reflection.

13. Rehabilitating space and places at Landsdowne building by infering on a vision with activities, uses, character and meaning by the concept of triangulation. For instance, a bin, a seating area and a food kiosk positioned close to an activity genereator produce more synergy in place-making.

14. For Mandi market, emphasizing the need of providing basic common facilities like cafes, toilets and parking through the space interventions while identifying the traffic movement pattern during events or festivals and trying to identify a city scale public space where happy communions can happen with a 'heads up' approach while focusing on the creation of cultural zones where art, artists and people in the creative sector could interact and be nurtured in a symbiotic environment.

\subsection{Conclusion}

The changing dynamics and the pattern of the three traditional market spaces in the central core of Mysuru city were reviewed upon the sphere of influence and significance factors. The heritage factor lies at the very epicenter of the study representing a timely opportunity to lead the charge in shaping and defining place-making. The markets and the spaces in context were analyzed combining with the very interface of physical, societal, environmental, and managerial aspects providing a likely means for tackling the challenge of cultural behaviour across different meanings associated with a "place" 
In this context, focus on the endogenous facet of the demand for place may be a key issue to achieve the vision of a quality livable place, it is also considerably important to re-connect with the people with a "heads up" approach, and understand the community, its aspirations and expectations on characteristics of good place-making spaces. Mysuru as a tourism centric city should develop a vision for market spaces as vibrant spaces and the people using them have a sense of ownership, such that both people and places will evolve over time and adapt to the changes and needs of the future generations to underline that a multi-dimensional and an interdisciplinary approach like place-making are essential in offering a broader solution to tackle the challenges of the urban public market spaces by facilitating the creation of a cultural creative ecosystem.

\section{References}

[1]. Ashworth, G. J. (2000). Heritage, Tourism and Places: A Review. Tourism Recreation Research, 25(1), 19- 29.

[2]. Crespi, M., \& Perez, M. (2015). Food markets: New tourism icons. In I. Tozsa \& A. Zatori (Eds.), Metropolitan Tourism Experience Development (pp. 127-139). Budapest: Cornivus University of Budapest.

[3]. City of Cambridge Community Development Department (2010), Lechemere Square Public Market: Preliminary feasibility study, Cambridge

[4]. Spitzer, T. M., \& Baum, H. (1995). Public Markets and Community Revitalization. Washington, DC: ULIthe Urban Land Institute and Project for Public Spaces. 
[5]. Redevelopment of Ghazipur Mandi, Delhi - Ishita Chandra (2017), B.Arch Thesis, Faculty of Architecture and Ekistics, Jamia Millia Islamia, New Delhi, Retrieved from https://www.architecturelive.in/b-archthesis-redevelopment-of-ghazipur-mandi-delhiishita-chandra-faculty-of-architecture-and-ekistics-jamiamillia-islamia-new-delhi/

[6]. Vani Vilas Market, Mandi Market Slipping into history (May 2010). Retrieved from https://timesofindia.indiatimes.com/city/mysuru/Vani-Vilas-Market-Mandi-Marketslipping-intohistory/articleshow/5878069.cms

[7]. Mehta, V. (2009). Look Closely and You Will See, Listen Carefully and You Will Hear: Urban Design and Social Interaction on Streets. Journal of Urban Design, 14(1), 29-64. Doi: $10.1080 / 13574800802452658$

[8]. Structural Review of Heritage Buildings in Mysore, Karnataka-Case Study of Devaraja Market and Landsdowne building (October 2016) prepared by the Tenants association of the Devaraja Market and Landsdowne building, Mysore

[9]. David O Neil (2005), Ten qualities of successful Public Markets, Project for Public Spaces (September 2005) Retrieved from https://www.pps.org/article/tencharacteristics-2

[10]. Gehl, J. (2017). Placemaking: The Public Realm's impact on value. Denmark. https://www.cbre.com/ research-and-reports/Global-Placemaking-Value-and-the-PublicRealm-May-2017

[11]. Placemaking In Practice- How It Works? Retrieved from https://artintelligent.com/placemaking/

[12]. Porada, B. (2013). Ten Ways to Transform Cities through Placemaking \& Public Spaces. Retrieved from Arch Daily website: http://www.archdaily.com/362988/ten-ways-totransform-cities-through-placemakingand-public-spaces

[13]. Gehl, J (2001). Life Between Buildings: Using Public Space. The Danish Architectural Press [Fifth Edition, originally published in 1971]

[14]. PPS_Placemaking. (2015). Creative Placemaking Webinar: Project for Public Spaces. 